\title{
PENGGAMBARAN 3 DIMENSI (3D) GEDUNG SEBAGAI PENJABARAN LEVEL OF DETAIL (LOD)
}

\author{
RINALDY, RENANDA ANDARI
}

\author{
Jurusan Teknik Geodesi \\ FTSP - Institut Teknologi Nasional, Bandung \\ Email: rinaldy583@gmail.com
}

\begin{abstract}
ABSTRAK
Setiap bangunan fisik memerlukan pemeliharaan dan perawatan, agar berfungsi dengan baik. Pengelolaan bangunan tersebut sangat memerlukan informasi atas obyek yang dimaksud, baik secara menyeluruh ataupun pada setiap bagian gedung. Salah satu cara yang dapat memudahkan hal tersebut adalah melalui visualisasi obyek secara menyeluruh dalam bentuk gambar digital 3D. Gambar digital bangunan, dapat dinyatakan dalam bentuk bagian obyek sebagai entity yang dapat dikaitkan secara langsung dengan Sistem Informasi Manajemen. Studi ini merupakan langkah awal penggambaran data gedung 3D yang berkembang dalam berbagai aspek teknis, baik pengelolaan data grafis maupun sistem informasi 3D dengan mengambil Gedung 18 Institut Teknologi Nasional Bandung sebagai studi kasus. Metode yang digunakan adalah teknik pengukuran interior, eksterior, dan penggabungan. Hasil penelitian ini berupa gambar gedung 3D yang dapat digunakan sebagai data penunjang dalam pemeliharaan dan perawatan gedung.
\end{abstract}

Kata kunci: penggambaran 3D, bangunan gedung, pemeliharaan, perawatan

\begin{abstract}
Each physical building need maintenance and treatments, in order to function properly. Building management requires information on the object in question, either as a whole or on any part of the building. One way to facilitate this is through visualization object as a whole in the form of 3D digital images. The digital image of the building, can be expressed in the shape of the object as an "entity" that can be attributed directly to the Management Information System. This study is intended as a first step depiction of 3D building data is developed in various technical aspects, both graphical and data management information system 3D by using Building 18 of Institut Teknologi Nasional Bandung as the case study. The methods used in this study are interior-exterior measurement and mosaicking. The result of this research is 3D building image which can be used as supporting data in the building maintenance and treatments.
\end{abstract}

Keywords: 3D drawing, building, maintenance, treatments 


\section{PENDAhUlUan}

"Bangunan gedung adalah wujud fisik hasil pekerjaan konstruksi yang menyatu dengan tempat kedudukannya, sebagian atau seluruhnya berada di atas, di dalam tanah dan air, yang berfungsi sebagai tempat manusia melakukan kegiatannya, baik untuk tempat tinggal, kegiatan keagamaan, kegiatan usaha, kegiatan sosial, budaya, maupun kegiatan khusus". (UU No. 28 Tahun 2008 Tentang Gedung). Bangunan gedung yang terus-menerus digunakan tentunya akan mengalami perubahan baik fisik, struktur, eksterior serta interior, sehingga dibutuhkan pemeliharaan dan perawatan yang dilakukan secara terus-menerus ataupun berkala. Pemeliharaan dan perawatan gedung sendiri bertujuan untuk menjaga keandalan bangunan gedung beserta prasarana agar selalu layak fungsi. Pemeliharaan yang dilakukan meliputi memperbaiki, mengganti bagian bangunan gedung, komponen, bahan bangunan, dan prasarana.

Pemeliharaan atau perawatan gedung yang akan dilakukan harus memiliki data konkret mengenai obyek yang terdapat pada bangunan gedung yang berguna untuk mengelola setiap kebutuhan yang diperlukan dalam evaluasi pemeliharaan serta perawatan. Untuk itu diperlukan data gambar gedung beserta basis data untuk menyediakan informasi di dalam mendukung pemeliharaan dan perawatan (Rusdiana, 2013). Menggambar data gedung harus merupakan data yang mewakili obyek-obyek yang ada pada bangunan gedung seperti kerangka bangunan (obyek primer), dinding, kusen, kaca, pintu, jendela, lantai hingga atap (obyek sekunder). Data tersebut dihasilkan melalui pengukuran posisi secara relatif, langsung maupun tidak langsung yang ditampilkan di dalam 3Dimensi (3D) (Dorji, 2010).

Pengolahan data gedung dalam 3D memerlukan software komputer yang dapat membangun serta mengolah gambar gedung 3D (Hees, 2006). Studi kasus yang akan dipilih dalam penelitian ini adalah Gedung 18 Jurusan Teknik Geodesi Fakultas Teknik Sipil dan Perencanaan Institut Teknologi Nasional, pemetaan 3D yang akan dilakukan bertujuan untuk mengevaluasi pemeliharaan serta perawatan exterior dan interior gedung 18. Data gambar gedung 3D diperlukan untuk merepresentasikan obyek-obyek, gambar gedung 3D adalah data yang menggambarkan bentuk atau kenampakan obyek di permukaan bumi, gambar gedung 3D ini menjadi entity (Luebke dkk. 2003). Setiap obyek bagian gedung menjadi informasi yang berbeda dan ditampilkan dalam bentuk 3D, sehingga informasi lebih lanjut dinyatakan dalam bentuk atribut. Tampilan 3D tersebut digambarkan dengan model-model visualisasi yang berbeda, jadi gambar gedung 3D yang diperlukan merupakan data pengukuran yang diolah agar dihasilkan kenampakan obyek dalam 3D menggunakan software Computer Aided Desaign (CAD) (Suparno, 2007).

\section{METODOLOGI}

Langkah awal dari studi adalah dengan melakukan studi literatur penulisan, persiapan pengukuran serta persiapan penggambaran sketsa, pelaksanaan pengukuran data eksterior dilakukan menggunakan alat ETS untuk mendapatkan ketinggian. Pada pengukuran interior dilakukan pengukuran jarak berdasarkan posisi relatif. Penggunaan alat pada studi ini adalah berupa 1 unit Electronic Total Station (ETS) Reflectorless, pita ukur, dan distometer. Studi kasus dilakukan pada Gedung 18 Institut Teknologi Nasional (Itenas) Bandung. 


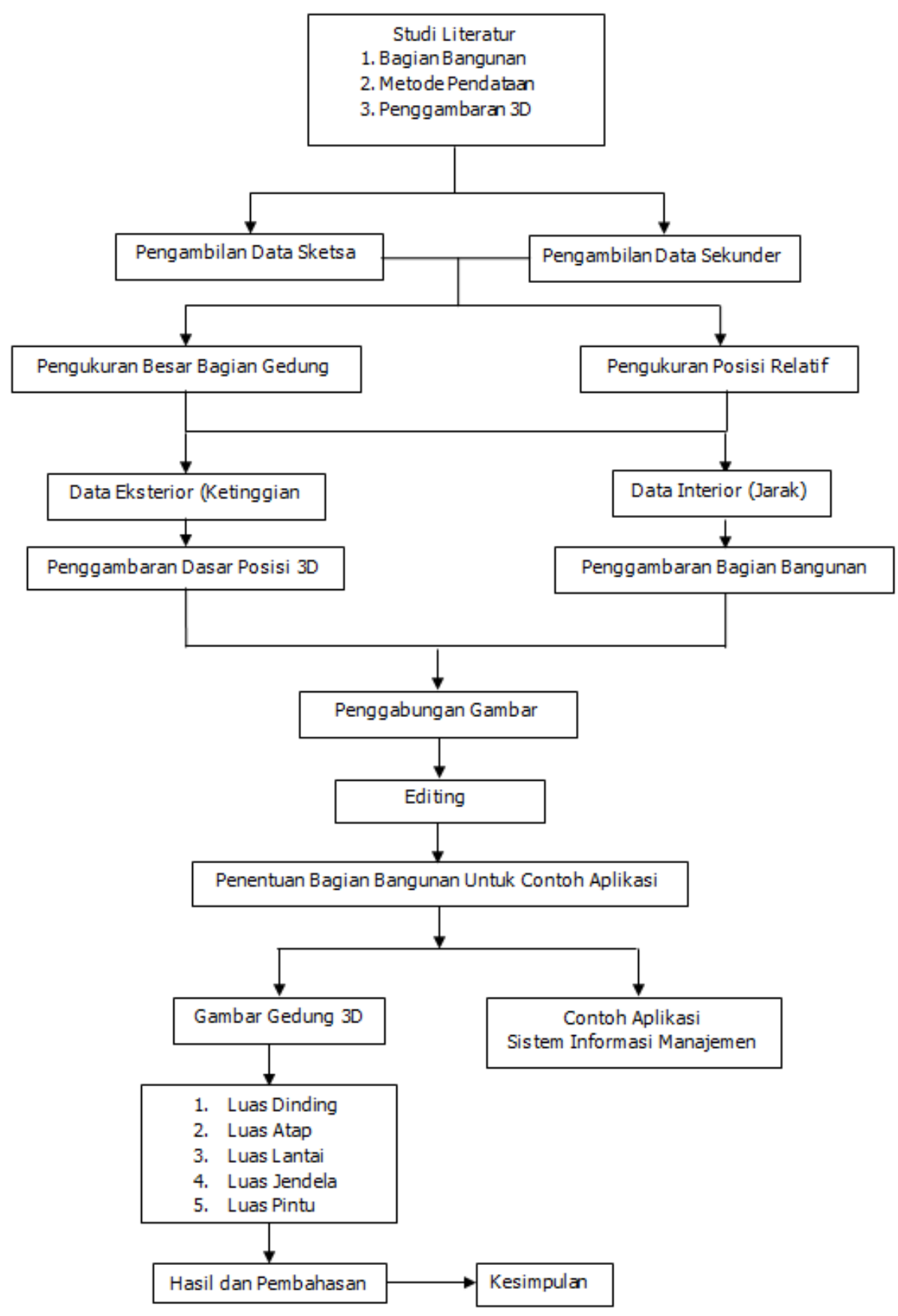

\section{Gambar 1. Diagram Alir Metodologi Penelitian}

Adapun penjelasan diagram alir di atas adalah sebagai berikut.

1) Pengambilan Data

Tahapan pengambilan data adalah mengumpulkan data-data pengukuran dan sketsa yang dibutuhkan. Pelaksanaan pengukuran data eksterior dilakukan menggunakan alat ETS untuk mendapatkan ketinggian. Pada pengukuran interior dilakukan pengukuran jarak berdasarkan posisi relatif.

2) Pelengkapan Data 
Pada tahapan ini dilakukan pelengkapan data-data yang belum lengkap (yang dapat dilihat pada saat kelengkapan sketsa) pada saat pengambilan data, maka dilakukan kembali pengambilan data. Jika sketsa telah lengkap, maka dilanjutkan pada proses selanjutnya yaitu penyajian hasil.

3) Penggambaran

Tahapan ini menyajikan data atau penggambaran. Data tersebut diinput ke dalam $C A D$, selanjutnya dilakukan proses editing dan disajikan secara visual menjadi gambar gedung 3D.

4) Hasil dan Pembahasan

Gambar gedung yang ditampilkan dalam 3D kemudian diinput sebagai entity untuk menunjang gambar gedung 18 terutama di dalam perhitungan luas obyek-obyek yang berguna dalam pemeliharaan gedung dan menyertakan data atribut sebagai informasi dari gambar gedung 3D tersebut.

5) Kesimpulan dan Saran

Selanjutnya setelah dilakukan tahapan pembahasan maka dilakukan penarikan kesimpulan terhadap pengumpulan data, pengolahan data, dan hasil olahan data Gedung 18 Itenas.

\section{HASIL DAN PEMBAHASAN}

Hasil dari studi ini adalah berupa data grafis 3D di dalam menunjang sistem informasi manejemen untuk pemeliharaan serta perawatan gedung. Pengukuran yang dilakukan pada pengambilan data adalah pengukuran ketinggian dan jarak berdasarkan posisi relatif untuk mendapatkan data eksterior dan interior. Dalam penggambaran serta penyajian software yang digunakan adalah $C A D$ dan untuk pembentukan basis data adalah dbconnect dan microsoft excel. Tujuan dari penggambaran data grafis 3D pada studi ini adalah untuk menghasilkan data perhitungan luas beberapa obyek gedung seperti, dinding, lantai, dan atap menggunakan tool explode, list dan distance pada CAD. Data perhitungan menjadi basis data untuk keperluan pemeliharaan serta perawatan Gedung 18 Itenas

\subsection{Pengolahan Data Bidang 2D dan Gambar Gedung 3D}

Pengolahan dilakukan untuk melihat perbedaan otomatisasi penggunaan tool di dalam membangun data bidang 2D menjadi gambar gedung 3D. Data penggambaran merupakan data hasil pengukuran obyek eksterior dan interior. Data yang telah dihasilkan merupakan beberapa sampel yang memiliki dimensi yang sama serta mewakili setiap obyek bangunan gedung. Data bidang 2D menggunakan tool line, polyline, dan center/radius (Gambar 2) dalam penggambaran yang kemudian dibangun menjadi gambar gedung 3D menggunakan tool extrude, polysolid, presspull, dan sweep. Gambar gedung 3D memiliki kompleksitas baik di dalam penggambaran, pemotongan, penggabungan, dan penentuan sudut pandang. 


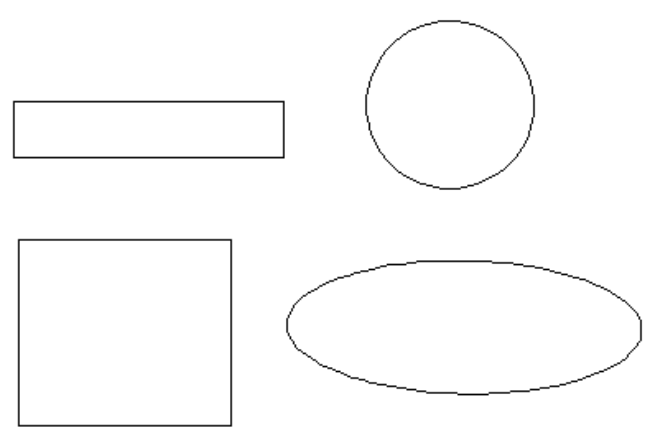

\section{Gambar 2. Penggambaran Berdasarkan Data Bidang 2D}

Contoh di dalam pembangunan gambar gedung 3D adalah penggambaran kusen yang dibangun berdasarkan bidang 2D persegi panjang, yang dibangun menggunakan data ketebalan, kemudian kusen yang telah berbentuk balok dipotong berdasarkan data masukan menggunakan substract. Data masukan tersebut berupa pintu serta jendela. Begitu juga dengan gambar gedung 3D lainnya. Obyek komponen gedung yang akan digambar adalah gambar berdasarkan data pengukuran bidang 2D yang kemudian dibangun menjadi gambar gedung 3D menggunakan data ketinggian dan ketebalan (Gambar 3).
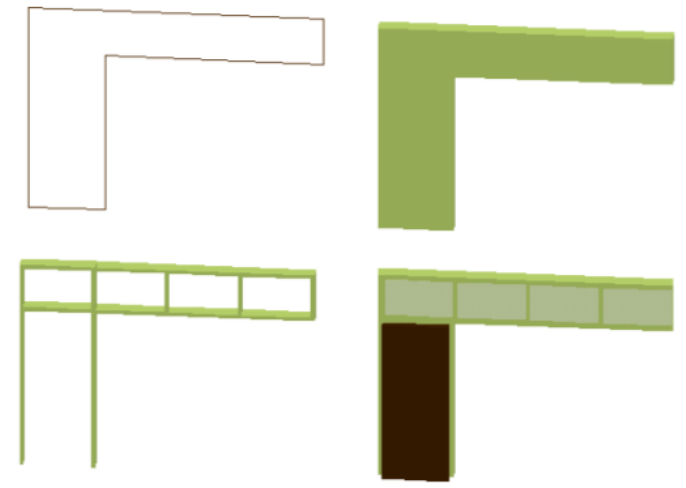

\section{Gambar 3. Penggambaran, Pemotongan, Penggabungan Berdasarkan Data Bidang 2D Menjadi Gambar Gedung 3D}

Membangun dinding pada gedung 18 yang bertujuan untuk menghasilkan data grafis 3D sesuai dengan data sketsa dilakukan dengan menggunakan metode tool polysolid, polysolid dapat membangun dinding dengan masukkan data ketinggian dan ketebalan dinding yang berbeda. Gedung 18 memiliki perbedaan ketebalan dinding yang berbeda khususnya pada lantai 1 maka otomatisasi penggunaan tool polysolid dirasa cukup efisien dan efektif.

Pengerjaan di dalam membangun dinding pada metode ini adalah digitasi berdasarkan sketsa ruang seperti pada gambar 4. 

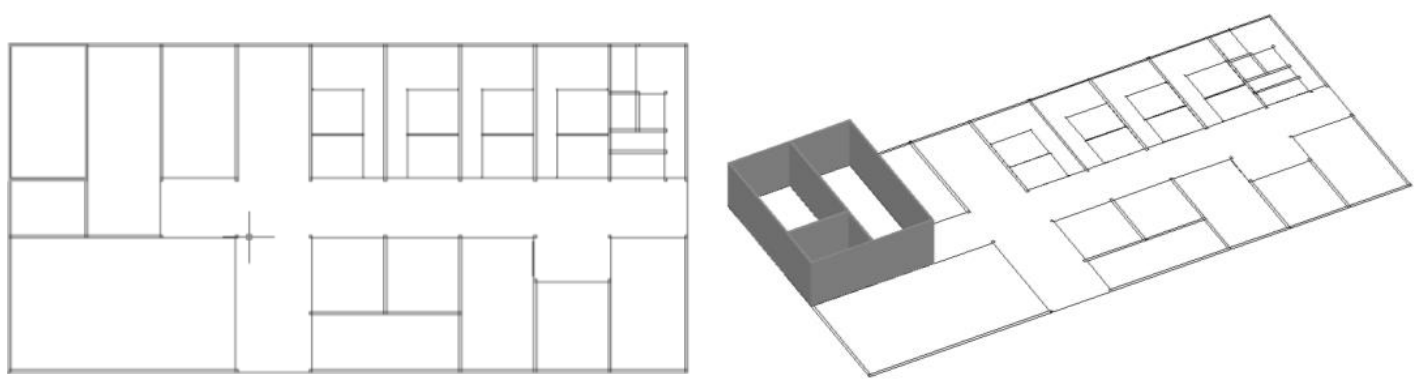

Gambar 4. Pembentukan Dinding Menggunakan Metode Tool Polysolid

Menjangkau tampilan data komponen setiap obyek data eksterior maupun interior atau obyek yang memiliki dimensi terbesar maupun terkecil dapat dilakukan melalui pemanfaatan tool view cube dan zoom extends. View cube merupakan tool yang juga diperuntukkan di dalam membantu perhitungan luas suatu obyek, dikarenakan view cube dapat memberikan sudut pandang yang diinginkan oleh pengguna $C A D$. Contoh di dalam pemanfaatan tool view cube dapat dilakukan untuk menjangkau tampilan bagian eksterior gedung seperti dinding pada tampak samping kanan-kiri maka sudut pandang yang dipilih south west isometric serta south east isometric, dan untuk dinding depan-belakang adalah front dan back (Gambar 5, 6, 7). Pemilihan sudut pandang dapat dilakukan pada otomatisasi tool pada bar view atau too/ tersendiri berbetuk balok yang tersedia pada pojok kanan atas lembar project CAD.

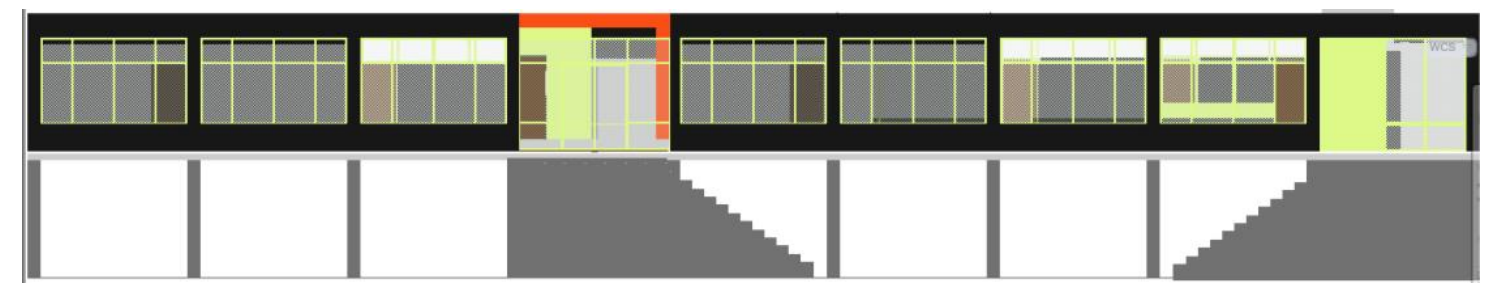

Gambar 5. Menjangkau Tampilan Front Gambar Gedung 3D Berdasarkan Sudut Pandang untuk Mendapatkan Hasil Luas Dinding Eksterior Gedung

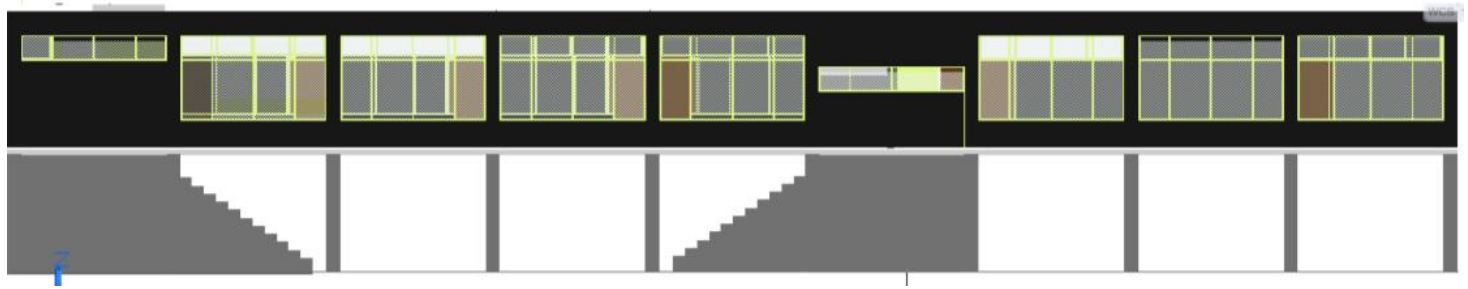

Gambar 6. Menjangkau Tampilan Back Gambar Gedung 3D Berdasarkan Sudut Pandang untuk Mendapatkan Hasil Luas Obyek Dinding Eksterior Gedung 


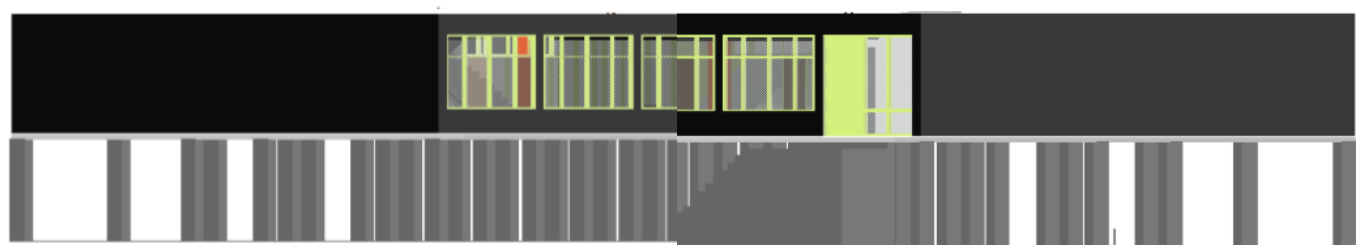

Gambar 7. Menjangkau Tampilan South West dan South East Gambar Gedung 3D Berdasarkan Sudut Pandang untuk Mendapatkan Hasil Luas Obyek Dinding Eksterior Gedung

Terwujudnya penjangkauan tampilan muka gambar gedung 3D yang kemudian dilanjutkan untuk perhitungan luas dilakukan menggunakan tool explode dan inquiry. Tool explode berguna untuk memisahkan setiap permukaan obyek sehingga dapat dihitung menggunakan tool inquiry. Pada tool inquiry terpadat beberapa bagian tool untuk menghitung setiap permukaan obyek yaitu, distance, region, list.

Metode penggunaan tool yang digunakan pada perhitungan luas adalah dengan menggunakan list. Beberapa metode tools lain juga dapat digunakan untuk menghitung luas namun berdasarkan wilayah studi kasus tools list dapat secara lansung memberikan data luas setiap sisi bidang pada gambar gedung 3D khususnya Gedung 18 (Gambar 8).

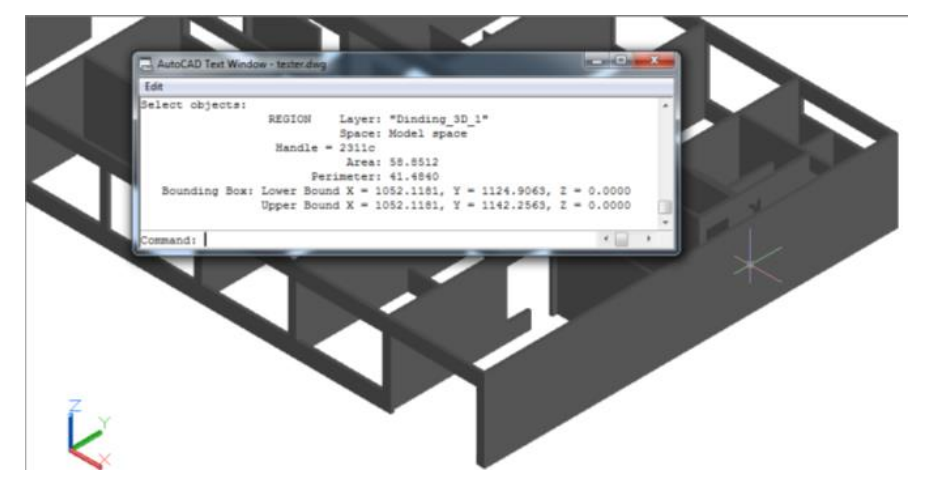

Gambar 8. Perhitungan Luas Menggunakan Metode Tool List

Pada bagian lantai dan atap data luas didapatkan dengan distance namun dengan tetap melakukan perhitungan (Gambar 9), distance hanya memberikan keterangan data jarak, maka untuk mendapatkan data luas atap dan lantai akan dilakukan perhitungan pada program microsoft exe/ seperti terlihat pada tabel 1. 


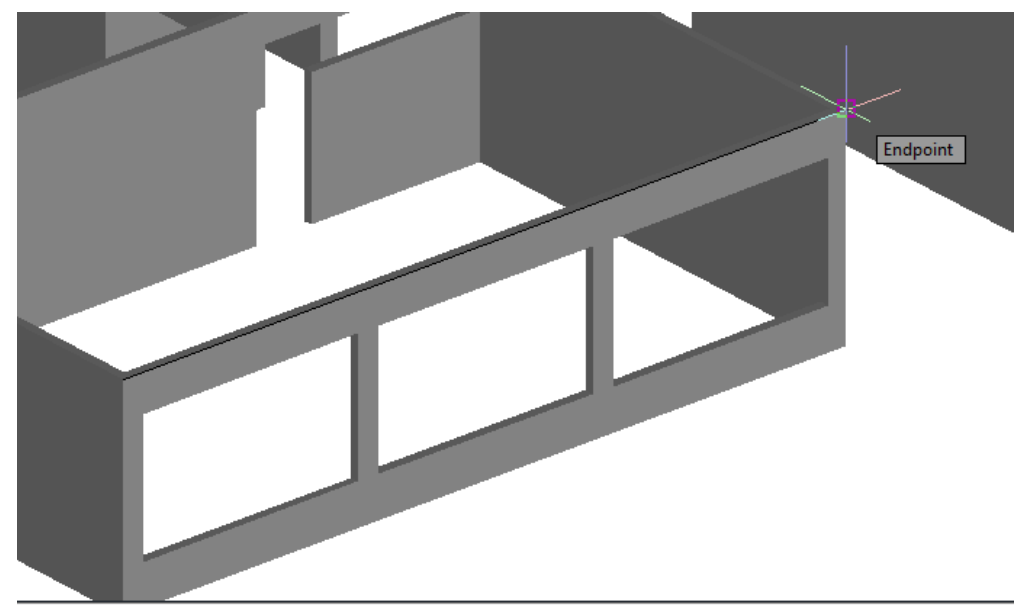

Gambar 9. Perhitungan Luas Menggunakan Metode Tool Distance

Tabel 1. Perhitungan Luas

\begin{tabular}{|c|c|c|c|c|c|}
\hline No & $\begin{array}{c}\text { ID } \\
\text { Ruang }\end{array}$ & Nama Ruang & $\begin{array}{l}\text { Luas Dinding } \\
\qquad\left(\mathrm{m}^{2}\right)\end{array}$ & $\begin{array}{l}\text { Luas Lantai } \\
\qquad\left(\mathbf{m}^{2}\right)\end{array}$ & $\begin{array}{c}\text { Luas Atap } \\
\left(\mathrm{m}^{2}\right)\end{array}$ \\
\hline 1 & 18101 & Ruang Dosen I & 82.365 & 26.410 & 23.543 \\
\hline 2 & 18102 & Ruang Administrasi & 41.002 & 17.556 & 15.586 \\
\hline 3 & 18103 & Ruang Seminar & 60.937 & 26.410 & 23.543 \\
\hline 4 & 18104 & Ruang Dosen II & 82.481 & 26.410 & 23.543 \\
\hline 5 & 18105 & Ruang Dosen III & 80.253 & 26.410 & 23.543 \\
\hline 6 & 18106 & Ruang Dosen IV & 82.481 & 26.410 & 23.543 \\
\hline 7 & 18107 & Ruang Kajur dan Kaprodi & & 61.095 & 47.085 \\
\hline 8 & 18108 & $\begin{array}{l}\text { Laboratorium Survei dan } \\
\text { Pemetaan }\end{array}$ & 88.730 & 78.108 & 68.620 \\
\hline 9 & 18109 & Laboratorium SIG & 100.174 & 82.288 & 70.628 \\
\hline 10 & 18110 & Ruang Asisten & 61.209 & 26.688 & 23.543 \\
\hline 11 & 18111 & Dapur & 25.203 & 3.640 & 3.134 \\
\hline 12 & 18112 & Toilet Wanita & 40.080 & 8.400 & 8.175 \\
\hline 13 & 18113 & Toilet Pria & 39.452 & 9.142 & 7.350 \\
\hline 14 & 18114 & Ruang Baca & & 30.782 & \\
\hline 15 & 18201 & Laboratorium Fotogrametri & 106.062 & 108.073 & 94.009 \\
\hline 16 & 18202 & Ruang Himpunan & 59.314 & 26.909 & 22.995 \\
\hline 17 & 18204 & Ruang Kelas & 94.840 & 82.133 & 70.466 \\
\hline 18 & 18205 & Studio Gambar & 74.846 & 54.905 & 47.085 \\
\hline 19 & 18206 & Ruang Penyimpanan Berkas & 93.091 & 83.825 & 70.789 \\
\hline 20 & 18207 & Ruang Kelas & 76.237 & 54.141 & 47.246 \\
\hline
\end{tabular}




\section{KESIMPULAN}

Berdasarkan studi dan uraian pembahasan yang telah dilakukan, dapat diambil kesimpulan sebagai berikut.

a. Gambar gedung 3D dan basis data Gedung 18 dapat digunakan sebagai data penunjang dalam pemeliharaan dan perawatan gedung.

b. Gambar gedung 3D merupakan data yang dibentuk berdasarkan data-data obyek gedung yang kemudian dibangun dan digabungkan menjadi data obyek 3D.

c. Gambar gedung 3D merupakan data hasil pengukuran eksterior dan interior gedung berdasarkan pengukuran data ketinggian dan jarak berdasarkan posisi relatif. Data tersebut merupakan data sampel yang mewakili beberapa komponen obyek gedung yang memiliki dimensi yang sama.

d. Pembentukan basis data merupakan data hasil perhitungan luasan obyek 3D Gedung 18.

e. Perhitungan luas total obyek 3D berdasarkan basis data gedung 18 dilakukan untuk memenuhi kebutuhan material di dalam pemeliharaan dan perawatan gedung.

\section{DAFTAR RUJUKAN}

Dorji, U. (2010). Maintenance Manual for Building. Maintenance Management Center: Jigme Namgyel Polytechnic. Dipetik 20 Juni 2016 dari http://www.jnp.edu.bt/sitefiles/downloads/ publications/ maintenance_manual.pdf

Hees, H. (2006). 3D Computer Graphics. Mainz: Pediapress. Dipetik 05 Juni 2016 dari http://read.pudn.com/downloads110/ebook/453151/3D\%20Computer\%20Graphics.pdf

Luebke, D., Reddy, M., Cohen, D, J., Varshney, A., Watson, B., dan Huebner, R. (2003). Level of Detail 3D Graphic. United States: Morgan Kaufmaan Publisher.

Rusdiana, H. A. (2013). Sistem Informasi Manajemen. Jakarta: Pustaka Setia.

Suparno, M. S. (2007). Professional 3D Modeling With AutoCAD 2013. Jakarta: PT Elex Media Komputindo.

UU No. 28 Tahun 2008 Tentang Gedung. Dipetik 26 Mei 2016 dari

http://www.bpkp.go.id/uu/filedownload/2/41/313.bpkp 